\title{
Prevalence of insomnia and use of hypnotics in seniors from the Łodz Province, Poland
}

\author{
FILIP BIELEC ${ }^{1, A-F}$, EMILIA KAMIŃSKA ${ }^{1, B, D-F}$, RAFAt DUDEK $^{1, B, D-F}$, \\ MAŁGORZATA KOZIARSKA-ROŚCISZEWSKA 2, 3, A, D, E, JACEK RYSZ2, A \\ ORCID ID: 0000-0002-5438-5837
}

\author{
${ }^{1}$ Students' Scientific Association of Family Medicine, Medical University of Lodz, Poland \\ ${ }^{2}$ Department of Nephrology, Hypertension and Family Medicine, Medical University of Lodz, Poland \\ ${ }^{3}$ Family Medicine Practice Vitaplus, Lodz, Poland
}

A - Study Design, B - Data Collection, C - Statistical Analysis, D - Data Interpretation, E - Manuscript Preparation, F - Literature Search, G - Funds Collection

Summary Background. Insomnia is a common sleep disorder among older people. It is characterized by difficulty with falling asleep, problems maintaining sleep and/or waking up too early. As a result, patients may complain about physical and mental fatigue and general malaise during the day. Hence, people suffering from insomnia often look for treatment options.

Objectives. To assess the frequency of insomnia in seniors; to establish the main predisposing factors and to evaluate the pharmacotherapy.

Material and methods. The study was conducted in the group of 298 aged 60+ residents of Lodz region, Poland. An anonymous questionnaire concerning lifestyle, sleep disorders, and hypnotics use was conducted by each patient. The Athens Insomnia Scale - a standardized questionnaire to diagnose insomnia was also performed. Patients were allocated into 2 groups: with and without insomnia. Collected data were statistically analyzed with the use of the $t$-student and chi-square tests.

Results. $25.8 \%$ of all patients were diagnosed with insomnia, and greater age, female sex, and mental or neurological disorders were found to be associated with insomnia in the elderly. Moreover, $22.8 \%$ of all patients took hypnotics despite the fact that $41.2 \%$ of them did not fulfill the criteria of insomnia. $\mathrm{H}_{1}$-blockers (32.4\%) were the most often used.

Conclusions. While $\mathrm{H}_{1}$-blockers are not recommended as the first choice insomnia drugs, they are the most frequently used hypnotics. A significant group of patients take these without medical recommendation. The implementation of a simple tool for diagnosing insomnia in everyday practice would be useful.

Key words: epidemiology, family practice, geriatrics, hypnotics and sedatives, sleep initiation and maintenance disorders.

Bielec F, Kamińska E, Dudek R, Koziarska-Rościszewska M, Rysz J. Prevalence of insomnia and use of hypnotics in seniors from the Lodz Province, Poland. Fam Med Prim Care Rev 2019; 21(1): 17-22, doi: https://doi.org/10.5114/fmpcr.2019.82973.

\section{Background}

Insomnia is a common disorder among the elderly all over the world. Epidemiological data indicate $20-50 \%$ prevalence in $60+$ people; in females predominantly [1-4]. The higher probability of sleep disturbances is associated with age-related organic brain lesions. Moreover, symptoms of sleep disorders may be triggered or intensified by metabolic, respiratory or cardiovascular diseases, which are especially common among older people [5]. The association between lifestyle and the higher risk of symptoms occurrence depicted by the insufficient quantity and/ /or quality of sleep has been proven. This risk was significantly lower among seniors who were physically and socially active [6].

Nonorganic insomnia is a disease described in the 10th edition of International Statistical Classification of Diseases and Related Health Problems (ICD-10) as a condition of unsatisfactory quantity and/or quality of sleep, which persists for a considerable period of time. It includes difficulties with falling asleep, staying asleep or having non-refreshing sleep at least 3 times a week for at least a 1-month period of time $[7,8]$. The essential aspect of insomnia is its negative influence on physical and mental wellbeing during the day, causing significant deterioration in quality of life $[9,10]$. The common occurrence of insomnia, its insufficient diagnosis rate and lack of effective treatment generate high costs for the health care system. People suffering from insomnia have worse workplace productivity as well. In ad- dition, they may not be able to properly play their roles in a family or a society. The risk of injuries as a result of accidents is also increased in patients with insomnia $[8,9]$.

The most common methods of insomnia treatment are hypnotics or sedative drugs $[1,8]$. However, using these may lead to addiction, disruptive side effects or worse daytime functioning $[6,8]$.

Benzodiazepines and non-benzodiazepine hypnotics (so-called "Z-drugs") are popular groups of drugs prescribed for patients suffering from insomnia. $\mathrm{H}_{1}$-blocker, herbal or antidepressant drugs are also used $[8,11]$. "Z-drugs", when compared to benzodiazepines, are more efficient, however, due to the high risk of addiction, both of these drug groups should only be used for a short time $[8,11,12]$. The use of hypnotics increases with patient's age and is more common among women than men [13]. A German study has revealed that these drugs are often prescribed despite the fact that they are potentially inappropriate or are redundant therapy for older people [14]. Therefore, it is essential to popularize other methods of insomnia treatment among patients and also among physicians. Of these, proper sleep hygiene or cognitive behavioral therapy can be even more effective therapy than medication $[11,13]$.

\section{Objectives}

The aim of this study is to assess the frequency of insomnia in a group of people aged 60 or more so as to determine the 
main risk factors of insomnia and to evaluate the pharmacotherapy.

\section{Material and methods}

The study was conducted in a group of 298 volunteers; 119 men (39.9\%) and 179 women (60.1\%); aged 60-87 (mean 69) - students of the University of the Third Age and primary care patients in the region of Lodz (Poland), diversified in gender and area of residence according to Statistics Poland data [15]. An original, anonymous questionnaire was used as a research method. It was designed on the basis of the ICD-10 definition of insomnia $[7,8]$. The questions concerned demographic data, lifestyle, the use of hypnotics and sleep disorders other than insomnia (Table 1). Hypnotics use was measured with a single question about names of currently used sleeping agents. Answers to the questions about sleep disorders other than insomnia were employed for identification of the group of respondents (answer "no" to each question) with insomnia possibly not associated with other sleep disorders. Furthermore, the Athens Insomnia Scale (AIS) validated for Polish conditions was used to assess insomnia prevalence. Altogether, 306 questionnaire forms were collected, 8 were excluded due to existing exclusion criteria - age under 60 and the absence of answers making insomnia diagnosis unclear.

\section{Table 1. Questions related to sleep disorders other than} insomnia

1. Do you occasionally fall asleep unexpectedly during the day? 2. Do you snore hard?

3. Do you often have a tingling sensation in your legs, strong urge to move them or you can't lie motionless in bed?

4. Do you usually sleep well, but just at the wrong time, so you get up very late or fall asleep very early?

5. Do you have any abnormal behavior in your sleep that troubles you or is dangerous (e.g., sleepwalking, night terrors, recurring nightmares)?

\section{Athens Insomnia Scale}

In Europe, AIS is recognized as an insomnia assessment tool, based on the ICD-10 criteria, with high sensitivity (93\%) and specificity (85\%). It consists of 8 questions -5 strictly concerning sleep problems and 3 relating to the consequences during the day resulting from the time and quality of sleep at night. Included are questions concern difficulty in falling asleep, waking up at night, waking up earlier than planned, total sleep time and overall sleep quality. The consequences during the day that the questionnaire lists as: decreased well-being, decreased day activity and daytime sleepiness. Each question refers to the symptoms that had occurred the previous month at least 3 times a week. Respondents are asked to rate each question on a scale from 0 to 3, where 0 means no problem and 3 means maximum severity of the issue. The resulting points give a score between 0 and 24, where 0 indicates total absence of insomnia symptoms and 24 means the most severe form of it [16].

According to the AIS original validation, insomnia can be diagnosed when the patient reaches $\geq 6$ points. Of note, clinical studies demonstrate a $90 \%$ scale efficacy in confirming or excluding the diagnosis of inorganic insomnia [16]. Furthermore, certain local differences forced the need for the Polish validation of AIS, according to which insomnia should be diagnosed with the result $\geq 8$. Satisfactory results were achieved $-94 \%$ correct diagnoses in patients with insomnia and $84 \%$ in those who are healthy. AIS is the first tool developed and used for assessing insomnia which has Polish validation [17].

In our study, AIS was used also to find a group of seniors suffering from adverse consequences during the day resulting from insomnia. For this purpose, we analyzed the answers to the last 3 questions of the AIS questionnaire. Respondents who described consequences during the day at least as "markedly decreased" or "considerable" were taken under consideration.

\section{Statistical analysis}

Values of all variables are represented as proportions or arithmetic mean. In the main study results, the subjects were divided into two groups: those with and without insomnia. The group without insomnia was a control group. The data were also subdivided into independent groups depending on the taking of hypnotics or the suffering from adverse consequences during the day resulting from insomnia. The data distribution was evaluated by applying the Shapiro-Wilk test. The $t$-student test for independent samples was used for comparison between quantitative variables, while Pearson chi-square test was applied for qualitative variables. The alpha $=0.05$ was considered statistically significant. Missing data were omitted and statistics in such cases were calculated for the adequately reduced groups. Potential risk factors for insomnia were: gender, BMI, education, area of residence, professional activity, physical activity, smoking, alcohol and coffee intake, coexistence of mental or neurological disorders, reporting other sleep disorders. Statistical analysis was completed using the Statistica 13 software (StatSoft Inc., USA).

The study was approved by The Medical University of Lodz Bioethical Committee (RNN/143/16/KE).

\section{Results}

\section{Insomnia}

From the total of 298 subjects, $77(25.8 \%)$ had AIS result $\geq 8$ (confirmation of insomnia) and $221(74.2 \%)$ had AIS result $<8$ (exclusion of insomnia). The mean age was 69 years. It was noted that older seniors, women and people with mental or neurological disorders were at greater risk for incidence of insomnia (Table 2).

\begin{tabular}{|l|l|l|l|l|}
\hline \multicolumn{6}{|l|}{ Table 2. Characteristics of the study participants in relation to the Athens Insomnia Scale } \\
\cline { 1 - 4 } & Total & AIS $<8$ & AIS $\geq 8$ & \multirow{2}{*}{ 8 } \\
\cline { 2 - 4 } & 298 & $221(74.2 \%)$ & $77(25.8 \%)$ & \\
\hline Age & $69 \pm 6.2$ & $68.5 \pm 5.9$ & $70.2 \pm 7$ & $\mathbf{0 . 0 3 6}$ \\
\hline $\begin{array}{l}\text { Gender } \\
\text { Male } \\
\text { Female }\end{array}$ & $119(39.9 \%)$ & $99(44.8 \%)$ & $20(26 \%)$ & \multirow{2}{*}{0.004} \\
\hline BMI & $179(60.1 \%)$ & $122(55.2 \%)$ & $57(74 \%)$ & \\
\hline $\begin{array}{l}\text { Area of residence } \\
\text { Urban } \\
\text { Rural }\end{array}$ & $27.4 \pm 3.9$ & $27.5 \pm 3.8$ & $27.1 \pm 4.1$ & 0.461 \\
\hline
\end{tabular}




\begin{tabular}{|c|c|c|c|c|}
\hline & Total & AIS $<8$ & AIS $\geq 8$ & $p$ \\
\hline & 298 & $221(74.2 \%)$ & $77(25.8 \%)$ & \\
\hline $\begin{array}{l}\text { Education } \\
\text { Primary } \\
\text { Vocational } \\
\text { Secondary } \\
\text { Higher }\end{array}$ & $\begin{array}{l}16(5.4 \%) \\
43(14.5 \%) \\
150(50.5 \%) \\
88(39.6 \%)\end{array}$ & $\begin{array}{l}7(3.2 \%) \\
33(14.9 \%) \\
114(51.6 \%) \\
67(30.3 \%)\end{array}$ & $\begin{array}{l}9(11.8 \%) \\
10(13.2 \%) \\
36(47.4 \%) \\
21(27.6 \%)\end{array}$ & 0.09 \\
\hline University of the $3^{\text {rd }}$ Age participant & $129(43.3 \%)$ & $91(41.2 \%)$ & $38(49.4 \%)$ & 0.214 \\
\hline $\begin{array}{l}\text { Professional activity } \\
\text { Active (or pensioner, but active) } \\
\text { Not active (pensioner or annuitant) }\end{array}$ & $\begin{array}{l}60(20.1 \%) \\
238(79.9 \%)\end{array}$ & $\begin{array}{l}45(20.4 \%) \\
176(79.6 \%)\end{array}$ & $\begin{array}{l}15(19.5 \%) \\
62(80.5 \%)\end{array}$ & 0.869 \\
\hline Physical activity >150 min./week & $108(36.2 \%)$ & $84(38 \%)$ & $24(31.2 \%)$ & 0.284 \\
\hline Cigarette smoking & $31(10.5 \%)$ & $19(8.7 \%)$ & $12(15.6 \%)$ & 0.089 \\
\hline $\begin{array}{l}\text { Alcohol intake } \\
\text { Never } \\
\text { Several times a year } \\
\text { Several times a month } \\
\text { Several times a week } \\
\text { Everyday }\end{array}$ & $\begin{array}{l}53(17.9 \%) \\
162(54.7 \%) \\
66(22.3 \%) \\
9(3 \%) \\
6(2 \%)\end{array}$ & $\begin{array}{l}33(15 \%) \\
124(56.4 \%) \\
52(23.6 \%) \\
9(4.1 \%) \\
2(0.9 \%)\end{array}$ & $\begin{array}{l}20(26.3 \%) \\
38(50 \%) \\
14(18.4 \%) \\
0 \\
4(5.3 \%)\end{array}$ & 0.289 \\
\hline $\begin{array}{l}\text { Coffee intake } \\
\text { Never } \\
1 \text { cup a day } \\
2-3 \text { cups a day } \\
>3 \text { cups a day }\end{array}$ & $\begin{array}{l}86(28.9 \%) \\
138(46.3 \%) \\
71(23.8 \%) \\
3(1 \%)\end{array}$ & $\begin{array}{l}63(28.5 \%) \\
102(46.2 \%) \\
54(24.4 \%) \\
2(0.9 \%)\end{array}$ & $\begin{array}{l}23(29.9 \%) \\
36(46.8 \%) \\
17(22.1 \%) \\
1(1.3 \%)\end{array}$ & 0.769 \\
\hline Mental or neurological disorders & $57(19.1 \%)$ & $35(15.8 \%)$ & $22(26.6 \%)$ & 0.014 \\
\hline Other sleep disorders & $269(90.3 \%)$ & $198(89.6 \%)$ & $71(92.2 \%)$ & 0.507 \\
\hline Daytime adverse consequences & $34(11.4 \%)$ & 0 & $34(44.2 \%)$ & $<0.001$ \\
\hline Hypnotics' use & $68(22.8 \%)$ & $28(12.7 \%)$ & $40(51.9 \%)$ & $<0.001$ \\
\hline $\begin{array}{l}\text { Groups of used hypnotics } \\
\mathrm{H}_{1} \text {-blockers } \\
\text { "Z-drugs" } \\
\text { Benzodiazepines } \\
\text { Antidepressants } \\
\text { Herbal products }\end{array}$ & $\begin{array}{l}22(32.4 \%) \\
16(23.5 \%) \\
15(22.1 \%) \\
6(8.8 \%) \\
13(19.1 \%)\end{array}$ & $\begin{array}{l}6(21.4 \%) \\
6(21.4 \%) \\
5(17.9 \%) \\
3(10.7 \%) \\
9(32.1 \%)\end{array}$ & $\begin{array}{l}16(40 \%) \\
10(25 \%) \\
10(25 \%) \\
3(7.5 \%) \\
4(10 \%)\end{array}$ & $\begin{array}{l}<0.001 \\
<0.001 \\
<0.001 \\
0.173 \\
0.679\end{array}$ \\
\hline Prescription drugs & 54 (79.4\%) & $18(64.3 \%)$ & 36 (90\%) & 0.009 \\
\hline
\end{tabular}

\section{The use of hypnotics}

Among seniors suffering from insomnia, $51.9 \%$ were taking hypnotics. The respondents most often used $\mathrm{H}_{1}$-blockers (40\%), more rarely "Z-drugs" and benzodiazepines (25\% each). This trend was independent of insomnia incidence, however, more frequent intake of these three drug classes was observed in older people with insomnia (Table 2). The active substances that were indicated most often: hydroxyzine $(30.9 \%)$, zolpidem (20.6\%), estazolam (13.2\%).

In general, hypnotic drugs were significantly much more often used by women, people with mental or neurological disorders
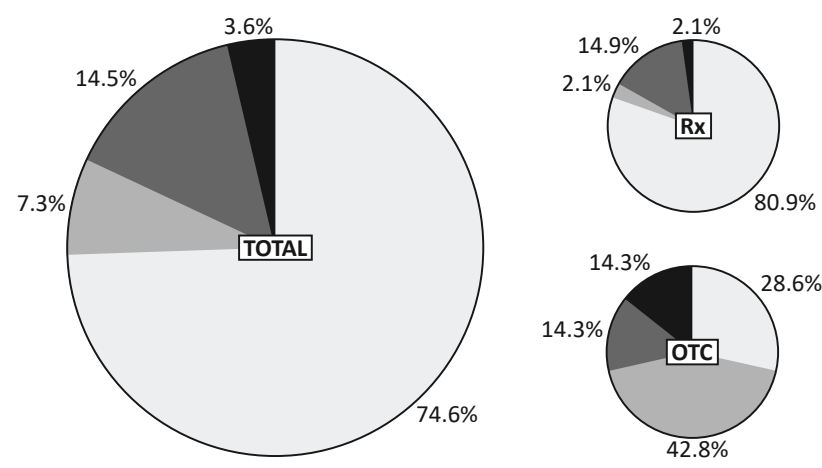

$\square$ physician $\square$ advertisment $\square$ family/friends and patients with AIS score $\geq 8$ (Table 3 ). What is more, $19.1 \%$ of all the subjects taking hypnotics admitted using herbal products (pharmaceuticals available over-the-counter), mainly composed of lemon balm leaves (Melissa officinalis), valerian root (Valeriana officinalis) or common hop cones (Humulus lupulus).

Respondents choosing hypnotics were primarily guided by a physician's consultation (74.5\%), but $26.5 \%$ used hypnotics without consultation. Over-the-counter drugs (mainly herbal products or combination drugs composed of NSAID and $\mathrm{H}_{1}$ -blocker) were taken mainly due to advertisement advice, while prescription medicines were self-administered after seeing a physician (Figure 1).
Figure 1. Main reasons for hypnotics use $(n=68$; legend: Rx - prescription drugs only, OTC - over-the-counter drugs only) 


\begin{tabular}{|c|c|c|c|}
\hline \multirow[t]{2}{*}{ Hypnotics' use } & No & Yes & \multirow[t]{2}{*}{$p$} \\
\hline & $230(77.2 \%)$ & $68(22.8 \%)$ & \\
\hline Age & $68.8 \pm 6.3$ & $69.5 \pm 5.8$ & 0.376 \\
\hline $\begin{array}{l}\text { Gender } \\
\text { Male } \\
\text { Female }\end{array}$ & $\begin{array}{l}102(44.3 \%) \\
128(55.7 \%)\end{array}$ & $\begin{array}{l}17(25 \%) \\
51(75 \%)\end{array}$ & 0.004 \\
\hline BMI & $27.6 \pm 3.8$ & $26.7 \pm 3.9$ & 0.105 \\
\hline Physical activity >150 min./week & $84(36.5 \%)$ & $24(35.3 \%)$ & 0.854 \\
\hline Cigarette smoking & $26(11.4 \%)$ & $5(7.4 \%)$ & 0.340 \\
\hline $\begin{array}{l}\text { Alcohol intake } \\
\text { Never } \\
\text { Several times a year } \\
\text { Several times a month } \\
\text { Several times a week } \\
\text { Everyday }\end{array}$ & $\begin{array}{l}32(14 \%) \\
132(57.9 \%) \\
52(22.8 \%) \\
8(3.5 \%) \\
4(1.8 \%)\end{array}$ & $\begin{array}{l}21(30.9 \%) \\
30(44.1 \%) \\
14(20.6 \%) \\
1(1.5 \%) \\
2(2.9 \%)\end{array}$ & 0.086 \\
\hline $\begin{array}{l}\text { Coffee intake } \\
\text { Never } \\
1 \text { cup a day } \\
2-3 \text { cups a day } \\
>3 \text { cups a day }\end{array}$ & $\begin{array}{l}68(29.6 \%) \\
103(44.8 \%) \\
58(25.2 \%) \\
1(0.4 \%)\end{array}$ & $\begin{array}{l}18(26.5 \%) \\
35(51.5 \%) \\
13(19.1 \%) \\
2(2.9 \%)\end{array}$ & 0.847 \\
\hline Mental or neurological disorders & $33(14.9 \%)$ & $24(31.2 \%)$ & $<0.001$ \\
\hline Insomnia (AIS $\geq 8$ ) & $37(16.1 \%)$ & $40(58.8 \%)$ & $<0.001$ \\
\hline Other sleep disorders & 210 (91.3\%) & 59 (86.8\%) & 0.269 \\
\hline
\end{tabular}

Table 4. Characteristics of the study participants in relation to the occurrence of adverse consequences during the day resulting from insomnia

\begin{tabular}{|c|c|c|c|}
\hline Symptoms occurrence & No & Yes & $p$ \\
\hline & $264(88.6 \%)$ & $34(11.4 \%)$ & \\
\hline Age & $68.6 \pm 5.9$ & $71.9 \pm 8$ & 0.004 \\
\hline $\begin{array}{c}\text { Gender } \\
\text { Male } \\
\text { Female }\end{array}$ & $\begin{array}{l}110(41.7 \%) \\
154(58.3 \%)\end{array}$ & $\begin{array}{l}9(26.5 \%) \\
25(73.5 \%)\end{array}$ & 0.089 \\
\hline BMI & $27.5 \pm 3.8$ & $26.9 \pm 4.6$ & 0.443 \\
\hline Physical activity >150 min./week & $100(37.9 \%)$ & $8(23.5 \%)$ & 0.102 \\
\hline Cigarette smoking & $22(8.4 \%)$ & $9(26.5 \%)$ & 0.001 \\
\hline $\begin{array}{l}\text { Alcohol intake } \\
\text { Never } \\
\text { Several times a year } \\
\text { Several times a month } \\
\text { Several times a week } \\
\text { Everyday }\end{array}$ & $\begin{array}{l}44(16.7 \%) \\
145(55.1 \%) \\
59(22.4 \%) \\
9(3.4 \%) \\
6(2.3 \%) \\
\end{array}$ & $\begin{array}{l}9 \text { (27.3\%) } \\
17(51.5 \%) \\
7(21.2 \%) \\
0 \\
0\end{array}$ & 0.095 \\
\hline $\begin{array}{l}\text { Coffee intake } \\
\text { Never } \\
1 \text { cup a day } \\
2-3 \text { cups a day } \\
>3 \text { cups a day }\end{array}$ & $\begin{array}{l}77(29.2 \%) \\
123(46.6 \%) \\
61(23.1 \%) \\
3(1.1 \%)\end{array}$ & $\begin{array}{l}9(26.5 \%) \\
15(44.1 \%) \\
10(29.4 \%) \\
0\end{array}$ & 0.625 \\
\hline Mental or neurological disorders & $50(18.9 \%)$ & $7(9.1 \%)$ & 0.819 \\
\hline Insomnia (AIS $\geq 8$ ) & $43(16.3 \%)$ & $34(100 \%)$ & $<0.001$ \\
\hline Other sleep disorders & $238(90.2 \%)$ & $31(91.2 \%)$ & 0.85 \\
\hline Hypnotics' use & $50(18.9 \%)$ & $18(52.9 \%)$ & $<0.001$ \\
\hline $\begin{array}{l}\text { Groups of used hypnotics } \\
\mathrm{H}_{1} \text {-blockers } \\
\text { "Z-drugs" } \\
\text { Benzodiazepines } \\
\text { Antidepressants } \\
\text { Herbal products }\end{array}$ & $\begin{array}{l}17(34 \%) \\
10(20 \%) \\
11(22 \%) \\
6(12 \%) \\
10(20 \%)\end{array}$ & $\begin{array}{l}5(27.8 \%) \\
6(33.3 \%) \\
4(22.2 \%) \\
0 \\
3(16.7 \%)\end{array}$ & $\begin{array}{l}0.083 \\
<0.001 \\
0.057 \\
0.376 \\
0.117\end{array}$ \\
\hline
\end{tabular}

\section{Adverse consequences during the day}

The occurrence of daytime symptoms associated with insomnia was reported by $11.4 \%$ of all the respondents. All of these individuals met the AIS diagnostic criteria for insomnia, and older seniors significantly more often noted such symp- toms. A statistically significant correlation between cigarette smoking and occurrence of the adverse consequences during the day was also observed. Seniors reporting such symptoms were taking hypnotics more often - especially from the "Z-drugs" group (Table 4). 


\section{Discussion}

Our study revealed that greater age, female gender and coexistence of mental or neurological disorders are the factors associated with developing insomnia - this fact is indicated also by the research of American, Polish, Norwegian and Australian scientists $[2,9,10,13,18-21]$. Other publications revealed the connection between insomnia and education, professional activity, physical activity, smoking, alcohol and coffee intake $[2,4$, $6,22]$. Our study did not confirm such results. This problem requires further study.

Hypnotics use was reported by $51.9 \%$ of all seniors with AIS score $\geq 8$, other Polish research showed similar data [18]. Those numbers are over 2 times more than in seniors in China and about 1.5 times more than in those in Australia. The difference may be a result of a different attitude towards sleeping disorder treatment in other cultures $[4,21]$. $\mathrm{H}_{1}$-blockers were the most frequently used drugs by older people suffering from insomnia, even though these drugs play a secondary role in insomnia management and may cause some side effects which may be dangerous in the senior population, e.g. drowsiness, confusion, impaired concentration and memory. The British Association for Psychopharmacology and The American Geriatrics Society emphasize that the maximum recommended duration of insomnia treatment is 2-4 weeks. However, hypnotics are often used permanently. This may result in the risk of addiction and severe side effects. Benzodiazepines (which are long-acting agents) in particular should be especially avoided in the older population due to their increased sensitivity and decreased metabolism. Such drugs also increase the risk of cognitive impairment, delirium and falls often leading to fractures. "Z-drugs", in contrast, do not interfere with sleep architecture and have relatively mild side effects in short-term treatment, hence, they are considered as the most appropriate choice in pharmacological insomnia treatment $[8,23]$. Although non-pharmacological methods (such as behavioral therapy) are recommended for insomnia management, British doctors have pointed out their low availability and Norwegians have revealed that older patients prefer pharmacological treatment of insomnia to non-pharmacological [13, 24]. This results in the more frequent prescription of hypnotics therapies.

We also assessed the frequency of administration of hypnotics and the main reasons their use. Our data show that $22.8 \%$ of all respondents used medications that ease falling asleep, $12.7 \%$ of whom did not suffer from insomnia according to AIS. Patients mainly used prescribed medicines, which might be associated with inadequate diagnoses and as a result of this - inadequate treatment. This situation may be due to the lack of experience with proper diagnostic tools, such as AIS. Three-quarter of all respondents used hypnotics guided by a physician, but what is alarming, $21.8 \%$ of all patients were taking hypnotics without any professional consultation. Indeed, $17 \%$ of the surveyed seniors were taking prescription hypnotics advised by a family, friends or an advertisement.

Spanish scientists have revealed that seniors treated with $\geq 8$ medicaments often $(>25 \%)$ received potentially incorrect pharmacological therapy. Accordingly, $28.6 \%$ of all prescriptions for benzodiazepines were issued without medical indications or in connection with inadequate drugs [25]. What is more, questions concerning insomnia and sleep disorders were notoriously omitted during the general practice appointments, according to Norwegian data. Only $8 \%$ of all physicians assessed sleep qual- ity using recommended tools such as sleep diaries or dedicated questionnaires [20]. In available publications, there is no data concerning Poland in this matter.

Adverse consequences during the day resulting from insomnia, such as physical and mental fatigue or general malaise, were observed by $11.4 \%$ of all respondents, all of who scored AIS $\geq 8$. Research conducted by Smith et al. also demonstrated the correlation between night insomnia and worse functioning during the day, as people with high quality and appropriate duration of sleep did not encounter similar symptoms [26]. On the other hand, Reid et al. noted a connection between lack of physical activity and daytime somnolence [6]. Our study showed that seniors presenting daytime side effects were much older, used "Z-drugs" and smoked cigarettes significantly more often than the rest of the respondents. It remains unclear whether these unpleasant symptoms appear due to the use of hypnotics or smoking, or if fatigue, general malaise and somnolence predispose seniors to take medications and smoke cigarettes. This issue requires further research.

\section{Strengths and limitations}

Our work is valuable because until now there were not many studies concerning sleep problems in older people from Eastern Europe. The respondents were diversified in gender and area of residence according to data presented by Statistics Poland [15]. The limitation of our study is also that only 68 respondents reported the use of hypnotics, hence, the possibility of statistical analysis of the hypnotics group is significantly reduced. It should be taken into account that the study included not only prescription drugs, but over-the-counter and herbal medicines too. Additionally, the answers were self-reported, which might influence the study outcome - the respondents could omit some information concerning embarrassing topics (e.g. about mental disorders).

\section{Conclusions}

1. In the examined group of $60+$ patients, greater age, female gender, and coexistence of mental or neurological disorders were found associated with insomnia occurrence.

2. In this study, most older people suffering from insomnia used hypnotics. The most popular were $\mathrm{H}_{1}$-blockers, despite the fact that these drugs are not indicated in insomnia treatment.

3. Seniors used hypnotics mainly because of a physician's recommendation, but $25.4 \%$ of all patients did so without it, including $21,8 \%$ using hypnotics without any professional advice.

4. Adverse consequences during the day resulting from insomnia were reported more frequently by older people who smoke. Seniors with these symptoms also used "Z-drugs" significantly more often.

5. The Athens Insomnia Scale should be included in general practice as it is a simple and accurate tool that could help physicians to diagnose insomnia quickly and thus prescribe appropriate therapy.

Acknowledgments. Authors would like to thank Professor Andrzej Koziarski, the Head of the University of the Third Age at the Lodz University of Technology and all participants of this study.

Source of funding: This work was funded from the authors' own resources. Conflicts of interest: The authors declare no conflicts of interest.

\section{References}

1. Haimov I, Shatil E. Cognitive training improves sleep quality and cognitive function among older adults with insomnia. PLOS ONE 2013; 8(4): e61390. 
2. Lichstein KL, Taylor DJ, McCrae CS, et al. Chapter 81 - Insomnia: epidemiology and risk factors. In: Kryger MH, Roth T, eds. Principles and practice of sleep medicine. 6th ed. Philadelphia, PA: Elsevier; 2017: 761-768.

3. Kim KW, Kang SH, Yoon IY, et al. Prevalence and clinical characteristics of insomnia and its subtypes in the Korean elderly. Arch Gerontol Geriatr 2017; 68: 68-75.

4. Wang YM, Chen HG, Song $\mathrm{M}$, et al. Prevalence of insomnia and its risk factors in older individuals: a community-based study in four cities of Hebei Province, China. Sleep Med 2016; 19: 116-122.

5. Kujawska-Danecka H, Nowicka-Sauer K, Hajduk A, et al. The prevalence of depression symptoms and other mental disorders among patients aged 65 years and older - screening in the rural community. Fam Med Prim Care Rev 2016; 18(3): 274-277.

6. Reid KJ, Baron KG, Lu B, et al. Aerobic exercise improves self-reported sleep and quality of life in older adults with insomnia. Sleep Med 2010; 11(9): 934-940.

7. World Health Organization. The ICD-10 classification of mental and behavioural disorders: clinical descriptions and diagnostic guidelines. Geneva: WHO; 1992.

8. Wilson SJ, Nutt DJ, Alford C, et al. British Association for Psychopharmacology consensus statement on evidence-based treatment of insomnia, parasomnias and circadian rhythm disorders. J Psychopharmacol 2010; 24(11): 1577-1601.

9. Wickwire EM, Shaya FT, Scharf SM. Health economics of insomnia treatments: the return on investment for a good night's sleep. Sleep Med Rev 2016; 30: 72-82.

10. Wojtas A, Ciszewski S. Epidemiologia bezsenności. Psychiatria 2011; 8(3): 79-83 (in Polish).

11. Grabska-Kobyłecka I, Nowak D. Sleep, insomnia and its treatment - a brief review of current knowledge on the subject with a special attention to herbal medicine. Pediatr Med Rodz 2014; 10(3): 270-277.

12. Andersen $A B$, Frydenberg M. Long-term use of zopiclone, zolpidem and zaleplon among Danish elderly and the association with sociodemographic factors and use of other drugs. Pharmacoepidemiol Drug Saf 2011; 20(4): 378-385.

13. Omvik S, Pallesen S, Bjorvatn B, et al. Patient characteristics and predictors of sleep medication use. Int Clin Psychopharmacol 2010; 25(2): 91-100.

14. Amann U, Schmedt N, Garbe E. Prescribing of potentially inappropriate medications for the elderly: an analysis based on the PRISCUS list. Dtsch Arztebl Int 2012; 109(5): 69-75.

15. Główny Urząd Statystyczny. Rocznik Statystyczny Rzeczypospolitej Polskiej. Warszawa: GUS; 2017 (in Polish).

16. Soldatos CR, Dikeos DG, Paparrigopoulos TJ. The diagnostic validity of the Athens Insomnia Scale. J Psychosom Res 2003; 55(3): 263$-267$.

17. Fornal-Pawłowska M, Wołyńczyk-Gmaj, Szelenberg W. Walidacja Ateńskiej Skali Bezsenności. Psychiatr Pol 2011; 65(2): $211-221$ (in Polish).

18. Wolińska W, Pawlak IE, Mroczek B. Coexistence of insomnia and chronic diseases in over 60 years old. Fam Med Prim Care Rev 2016; 18(3): 364-367.

19. Dudzińska M, Neć M, Zwolak A, et al. Bezsenność - istotny problem w codziennej praktyce lekarskiej - doniesienia wstępne. Fam Med Prim Care Rev 2015; 17(2): 90-93 (in Polish).

20. Bjorvatn B, Meland E, Flo E, Mildestvedt T. High prevalence of insomnia and hypnotic use in patients visiting their general practitioner. Fam Pract 2017; 34(1): 20-24.

21. Almeida OP, Pfaff JJ. Sleep complaints among older general practice patients: asociation with depression. Br J Gen Pract 2005; 55(520): 864-866.

22. Clark I, Landolt HP. Coffee, caffeine, and sleep: a systematic review of epidemiological studies and randomized controlled trials. Sleep Med Rev 2017; 31: 70-78.

23. American Geriatrics Society 2015 Beers Criteria Update Expert Panel. American Geriatrics Society 2015 Updated beers criteria for potentially inappropriate medication use in older adults. J Am Geriatr Soc 2015; 63(11): 2227-2246.

24. Everitt $\mathrm{H}, \mathrm{McDermott} \mathrm{L}$, Leydon G, et al. GPs' management strategies for patients with insomnia: a survey and qualitative interview study. Br J Gen Pract 2014; 64(619): e112-e119.

25. Campins L, Serra-Prat M, Gózalo I, et al. Randomized controlled trial of an intervention to improve drug appropriateness in communitydwelling polymedicated elderly people. Fam Pract 2017; 34(1): 36-42.

26. Smith RA, Lack LC, Lovato N, et al. The relationship between a night's sleep and subsequent daytime functioning in older poor and good sleepers. J Sleep Res 2015; 24(1): 40-46.

Tables: 4

Figures: 0

References: 26

Received: 30.08 .2018

Reviewed: 1.09.2018

Accepted: 7.10.2018

Address for correspondence:

Małgorzata Koziarska-Rościszewska, MD, PhD

Klinika Nefrologii, Nadciśnienia Tętniczego i Medycyny Rodzinnej UM w Łodzi

ul. Żeromskiego 113

90-549 Łódź

Polska

Tel.: +48 42 63-93-750

E-mail: malgorzata.koziarska-rosciszewska@umed.lodz.pl 